Article

\title{
On the Application of Bipolar Electrochemistry to Characterise the Localised Corrosion Behaviour of Type 420 Ferritic Stainless Steel
}

\author{
Yiqi Zhou ${ }^{1, *(\mathbb{D})}$ and Dirk Lars Engelberg ${ }^{1,2}$ (D) \\ 1 Corrosion \& Protection Centre, Department of Materials, School of Natural Sciences, \\ The University of Manchester, Manchester M13 9PL, UK; D.Engelberg@manchester.ac.uk \\ 2 Materials Performance Centre, The University of Manchester, Manchester M13 9PL, UK \\ * Correspondence: Yiqi.Zhou@manchester.ac.uk; Tel.: +44-(0)-161-306-5952
}

Received: 23 May 2020; Accepted: 13 June 2020; Published: 15 June 2020

\begin{abstract}
Bipolar electrochemistry has been applied to Type 420 ferritic stainless steel in order to determine the full spectrum of anodic-to-cathodic polarisation behaviour. The occurrence of crevice corrosion, pitting corrosion in combination with general corrosion, pitting corrosion only, general corrosion only, followed by a cathodic region has been observed. Instances of pitting corrosion initiated near chromium-rich carbides with $\mathrm{Cr}_{23} \mathrm{C}_{6}, \mathrm{Cr}_{3} \mathrm{C}_{2}$, and $\mathrm{Cr}_{7} \mathrm{C}_{3}$ identified as pit nucleation sites. The observed pit growth kinetics were independent of the electrochemical over-potential. Characterisation of the pit size distributions supports the presence of a critical dissolved volume for the transition of metastable to stable pit growth and pit coalescence.
\end{abstract}

Keywords: stainless steel; bipolar electrochemistry; pitting corrosion; chromium carbides; pit growth factor

Highlights: The application of bipolar electrochemistry for observing pit growth kinetics and pit coalescence has been demonstrated.

$\mathrm{Cr}_{23} \mathrm{C}_{6}, \mathrm{Cr}_{3} \mathrm{C}_{2}$, and $\mathrm{Cr}_{7} \mathrm{C}_{3}$ have been identified as pit nucleation sites.

A critical dissolved pit volume has been observed for the transition to stable pit growth.

\section{Introduction}

The application of bipolar electrochemistry provides access to the full spectrum of anodic-to-cathodic reactions along a bipolar electrode (BPE) [1-4]. In earlier studies, bipolar electrochemistry was applied for electro-syntheses, in photo electrochemical cells, for battery research, high throughput deposition of metals, and corrosion investigations [5-7]. In a nutshell, bipolar electrochemistry combines a non-contact experimental setup with the ability of fast throughput corrosion screening, with access to all anodic and cathodic reactions in one experiment [1-3].

Stainless steels are prone to pitting corrosion in halide containing environments. In general, pitting corrosion is a rapid metal dissolution process, affected by the applied electrochemical potential, concentration of halides, microstructure, and electrolyte temperature $[8,9]$. At the pit initiation stage, all pits are considered to be metastable, followed by either re-passivation or the formation of stable pits $[10,11]$. The development of stable pits requires a critical pitting potential $\left(\mathrm{E}_{\mathrm{pit}}\right)$ and minimum critical pitting temperature (CPT) [12,13]. Changes in exposure temperature typically do not affect pit morphology, but the applied potential, microstructure condition, and $\mathrm{Cl}^{-}$concentration can influence the resulting pit shape [1,9]. In duplex stainless steel, the pit morphology is also influenced by the ratio, size, and distribution of the austenite and ferrite crystallographic phases [14,15].

Ferritic stainless steels have a low thermal expansion, high yield strength and stiffness, and good deformation behaviour, with excellent stress corrosion cracking (SCC) resistance [16,17]. Type 420 ferritic 
stainless steel is a hardenable stainless steel grade, with a $\mathrm{Cr}$ concentration between $12 \%$ and $14 \%$ and a high carbon content [18]. Type 420 is typically in service with a martensitic microstructure, obtained via austenitisation treatment and quenching from annealed microstructures. The final microstructure contains chromium carbides, and the corrosion behaviour of this microstructure condition is dependent on austenitisation temperature, quench rate, and tempering treatments [19,20]. In its annealed condition, Type 420 stainless steel has a ferritic microstructure, which makes the microstructure easier to machine into shapes and structures [21]. After austenitisation treatment, the chromium carbides generally dissolve into the matrix, with subsequent tempering applied in order to improve the ductility and toughness by changing the microstructure, secondary phase and carbide distribution, and the fraction of the retained austenite [22-24].

The work reported in this paper provides insight into the pitting corrosion behaviour of annealed Type 420 ferritic stainless steel via the application of a bipolar electrochemistry approach. The aim is to obtain information about the relationship between the electrochemical potential and the corrosion behaviour of this alloy, with a focus on determining pit nucleation sites and the associated growth kinetics.

\section{Materials and Experimental Methods}

Solution annealed Type 420 stainless steel with a composition (wt \%) of $13.7 \mathrm{Cr}, 0.46 \mathrm{C}, 0.47 \mathrm{Si}$, $0.39 \mathrm{Mn}$, and Fe (bal.) was used in this study. The stainless steel had a hardness of $198 \pm 4 \mathrm{HV}_{0.5}$, indicating a soft annealed microstructure condition. Micro hardness was measured with a Buehler Micromet Tester, using an applied load of $4.903 \mathrm{~N}\left(\mathrm{HV}_{0.5}\right)$, with the mean and standard deviation determined with five measurements.

Figure 1a shows the setup for the bipolar electrochemistry testing. With a sufficiently high potential across the $\mathrm{BPE}$, oxidation reactions occur close to the negative feeder electrode, and vice versa for the reduction reactions which occur close to the positive feeder electrode. Two different BPE samples were used for carrying out the bipolar experiments, with dimensions of $30 \times 10 \times 1.2 \mathrm{~mm}^{3}$ (length $\times$ width $\times$ thickness) and $50 \times 20 \times 1.2 \mathrm{~mm}^{3}$. The BPE samples were mounted in Araldite resin, with the exposed area ground to 1200 grit, followed by polishing to a $1 \mu \mathrm{m}$ diamond paste finish. The shorter $(30 \mathrm{~mm})$ sample was used to explore the pit nucleation sites, with the longer $(50 \mathrm{~mm})$ sample then applied for studying pit growth, demonstrating the versatility of this technique.
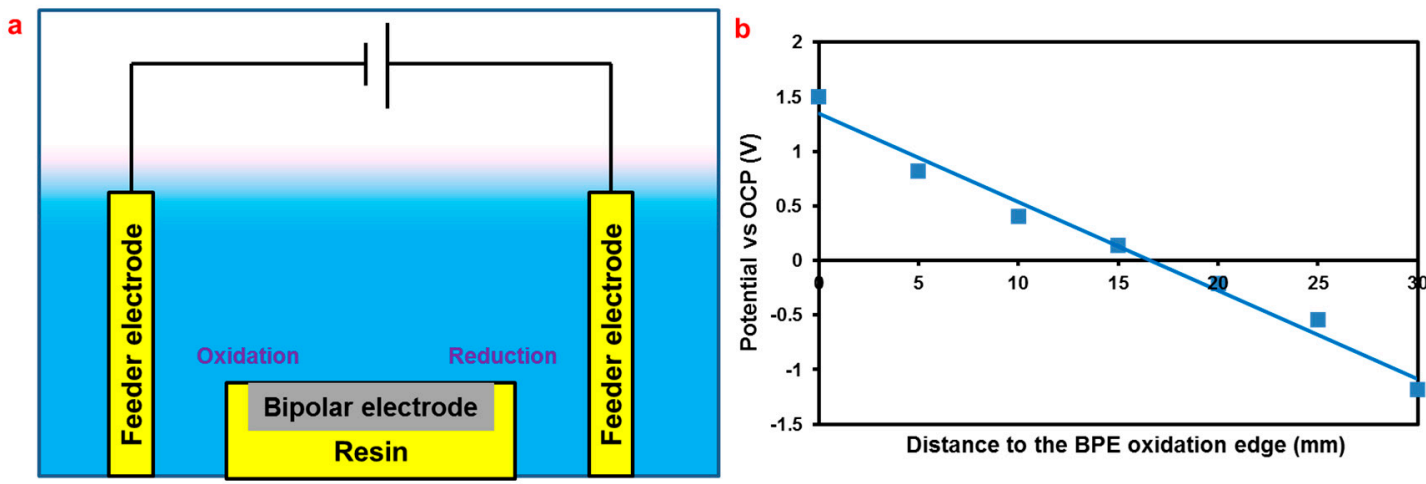

Figure 1. (a) A schematic diagram of the bipolar electrochemistry setup, and (b) the measured potential distribution on the bipolar electrode (BPE) (30 mm length) using a Luggin capillary connected to the saturated calomel electrode (SCE).

The $30 \mathrm{~mm}$ long BPE had a distance of $60 \mathrm{~mm}$ between the feeder electrodes. For the $50 \mathrm{~mm} \mathrm{BPE}$, the distance between the two feeder electrodes was set to $75 \mathrm{~mm}$. Both BPEs were centred between the two feeder electrodes, with an applied potentio-static potential of $10 \mathrm{~V}$ acting on the feeder electrodes. The electrolyte was $0.1 \mathrm{M} \mathrm{HCl}$ with a volume of $200 \mathrm{~mL}$, with experiments carried out up to $30 \mathrm{~min}$. The surface area of each platinum feeder electrode was $4 \mathrm{~cm}^{2}$. 
Figure $1 \mathrm{~b}$ demonstrates the potential gradient acting along the BPE, which was measured using a Luggin capillary connected to a saturated calomel electrode (SCE). The Luggin capillary was set $\approx 1 \mathrm{~mm}$ above the centre line of the BPE surface, which was in turn connected to a copper wire and an IVIUM-Compactstat in order to determine the local potential. To measure the local potential during the bipolar electrochemistry experiments, the open circuit potential (OCP) was stabilised first, and the power supply of the feeder electrodes was then switched on. The reported potential change on the $\mathrm{y}$-axis is the difference of the measured potential with respect to OCP, which can be described as the acting over-potential along the BPE.

All Type 420 ferritic BPE samples were washed with soap and dried in hot air after completing the bipolar electrochemistry experiments. The surface morphology of the tested samples was measured via laser scanning confocal microscopy, using a Keyence VK-X200K (Keyence Corporation, Osaka, Japan). For the electron backscatter diffraction (EBSD) and angle selective backscatter (AsB) microstructure analyses, the samples were ground to 4000 grit and polished to a $0.25 \mu \mathrm{m}$ diamond paste finish, followed by fine polishing with oxide polishing suspensions (OPS) of colloidal silica. A Zeiss Sigma VP FEG-SEM (Zeiss, Jena, Germany) was used for scanning electron microscopy (SEM) imaging at $1.5 \mathrm{kV}$, with high-resolution EBSD analysis carried out at $15 \mathrm{kV}$ and a step size of $33 \mathrm{~nm}$. An FEG-FEI Quanta 250 SEM (FEI Company, Hillsboro, OR, USA) was used for the energy dispersive x-ray (EDX) elemental analysis using $20 \mathrm{kV}$.

\section{Results and Discussion}

The microstructure of Type 420 stainless steel is shown in Figure 2a, highlighting the different grain orientations of the annealed ferritic matrix. A small number of dark spots, shown by the arrows in Figure 2, were present in the micrograph, possibly due to the metallographic preparation method (OPS polish). Chromium carbides were omnipresent in the matrix, with Figure $2 \mathrm{~b}$ showing typical morphologies in the form of one smaller $(\approx 100 \mathrm{~nm})$ and three larger ellipsoids $(\approx 800 \mathrm{~nm})$. The microstructure had typical chromium carbide sizes of up to $\approx 2 \mu \mathrm{m}$.
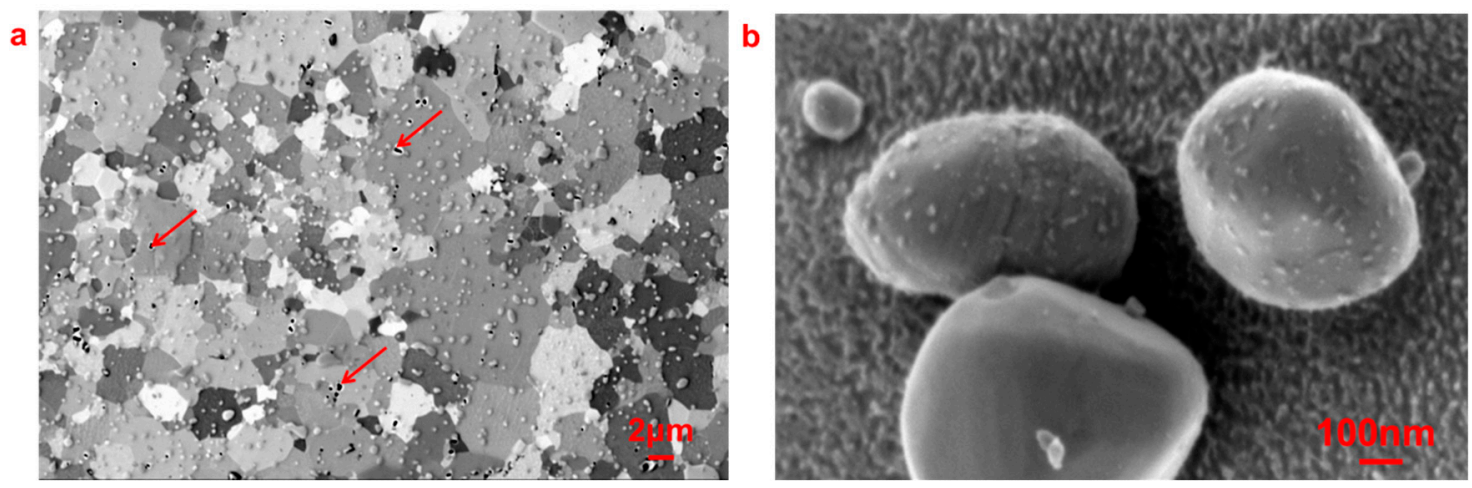

Figure 2. (a) AsB SEM image of Type 420 stainless steel with the arrows showing voids, and (b) typical size and shape of chromium carbides.

Figure 3a shows a SEM image of the Type 420 stainless steel with carbides present at triple junctions, along grain boundaries, and within grains, with the parameters of the possible carbides in this material listed in Table 1. The EDX images in Figure 3 confirm that all observed particles were chromium-rich carbides, with some containing higher Mn contents. The latter is related to the process annealing treatment, where $M n$ diffuses into the $\mathrm{M}_{23} \mathrm{C}_{6}$ [25]. $\mathrm{M}_{23} \mathrm{C}_{6}$ was homogenously distributed in the matrix, with the EBSD map in Figure 3 b showing the carbides, identified as $\mathrm{Cr}_{23} \mathrm{C}_{6}, \mathrm{Cr}_{3} \mathrm{C}_{2}$, and $\mathrm{Cr}_{7} \mathrm{C}_{3}$. The other two carbide types $\left(\mathrm{Cr}_{3} \mathrm{C}, \mathrm{CrC}\right)$ were not observed here in our study. 
a

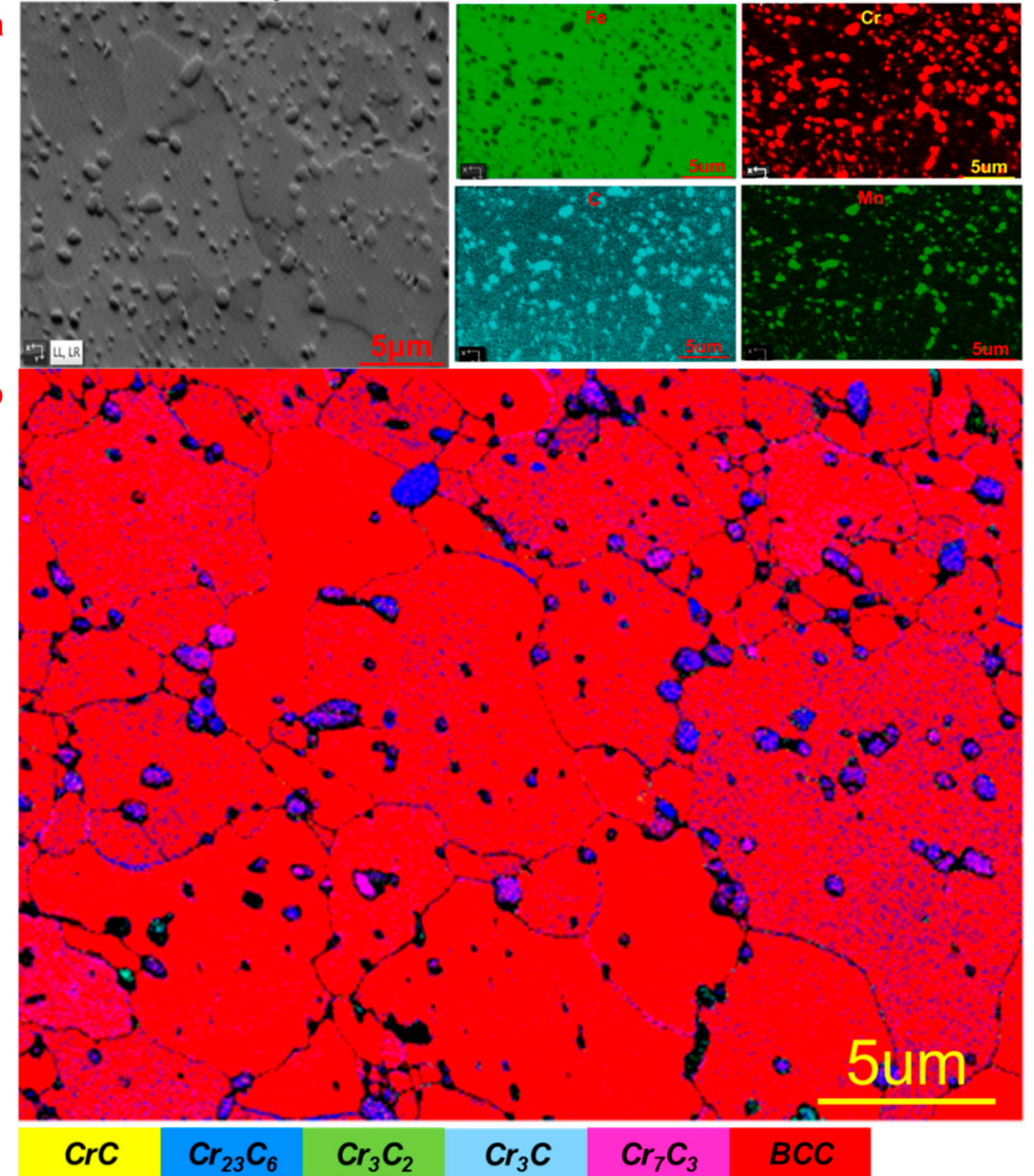

Figure 3. (a) SEM image of Type 420 ferritic stainless steel with EDX elemental maps of $\mathrm{Cr}, \mathrm{Fe}, \mathrm{C}$, and $\mathrm{Mn}$, and (b) high-resolution EBSD map highlighting chromium carbides (BCC = body centred cubic, ferritic matrix).

Table 1. Database with crystallographic parameters for electron backscatter diffraction (EBSD) phase identification from Inorganic Crystal Structure Database (ICSD) and the Aztec EBSD software (Version 4.2, Oxford Instruments, Abingdon, UK).

\begin{tabular}{ccccccccc}
\hline Phase & $\mathbf{A}$ & $\mathbf{B}$ & $\mathbf{C}$ & Alpha & Beta & Gamma & Space Group & Database \\
\hline $\mathrm{Fe} 3 \mathrm{C}$ & $5.11 \AA$ & $6.78 \AA$ & $4.54 \AA$ & $90.00^{\circ}$ & $90.00^{\circ}$ & $90.00^{\circ}$ & 62 & $\mathrm{HKL}$ \\
$\mathrm{Iron} \mathrm{bcc}$ & $2.87 \AA$ & $2.87 \AA$ & $2.87 \AA$ & $90.00^{\circ}$ & $90.00^{\circ}$ & $90.00^{\circ}$ & 229 & $\mathrm{HKL}$ \\
$\mathrm{Cr} 3 \mathrm{C}$ & $5.12 \AA$ & $6.80 \AA$ & $4.58 \AA$ & $90.00^{\circ}$ & $90.00^{\circ}$ & $90.00^{\circ}$ & 62 & $\mathrm{ICSD}$ \\
$\mathrm{Cr} 3 \mathrm{C} 2$ & $5.53 \AA$ & $11.49 \AA$ & $2.83 \AA$ & $90.00^{\circ}$ & $90.00^{\circ}$ & $90.00^{\circ}$ & 62 & $\mathrm{ICSD}$ \\
$\mathrm{Cr} \mathrm{C} 3$ & $4.53 \AA$ & $7.01 \AA$ & $12.14 \AA$ & $90.00^{\circ}$ & $90.00^{\circ}$ & $90.00^{\circ}$ & 62 & $\mathrm{ICSD}$ \\
$\mathrm{Cr} 23 C 6$ & $10.66 \AA$ & $10.66 \AA$ & $10.66 \AA$ & $90.00^{\circ}$ & $90.00^{\circ}$ & $90.00^{\circ}$ & 225 & $\mathrm{ICSD}$ \\
$\mathrm{Cr} C$ & $4.03 \AA$ & $4.03 \AA$ & $4.03 \AA$ & $90.00^{\circ}$ & $90.00^{\circ}$ & $90.00^{\circ}$ & 225 & ICSD \\
\hline
\end{tabular}

Chromium carbides and the ferritic matrix typically form via austenitisation heat treatments and subsequent cooling [26]. During the annealing process, $\mathrm{M}_{3} \mathrm{C}$ precipitate first and then transform into $\mathrm{M}_{7} \mathrm{C}_{3}$, and finally into $\mathrm{M}_{23} \mathrm{C}_{6}$ [27]. For long annealing times, metastable carbides either dissolve or transform into $\mathrm{Cr}_{23} \mathrm{C}_{6}$, which is the most thermodynamically stable carbide phase in this system [25]. The chromium carbide sizes shown in Figure $3 b$ decrease from $\mathrm{Cr}_{23} \mathrm{C}_{6}, \mathrm{Cr}_{7} \mathrm{C}_{3}$ to $\mathrm{Cr}_{3} \mathrm{C}_{2}$ as the $\mathrm{Cr}_{3} \mathrm{C}_{2}$ is formed first. 


\subsection{Pit Nucleation Sites}

Bipolar electrochemistry testing was carried out to identify the pit nucleation sites in this material. Figure 4 shows the $30 \mathrm{~mm}$ long BPE electrode with three distinctive regions highlighted after bipolar testing. From the BPE oxidation edge on the left to the reduction edge on the right, the overall corrosion response showed crevice corrosion at the edges, pitting corrosion surrounded by general corrosion, general corrosion only, and a large cathodic region.

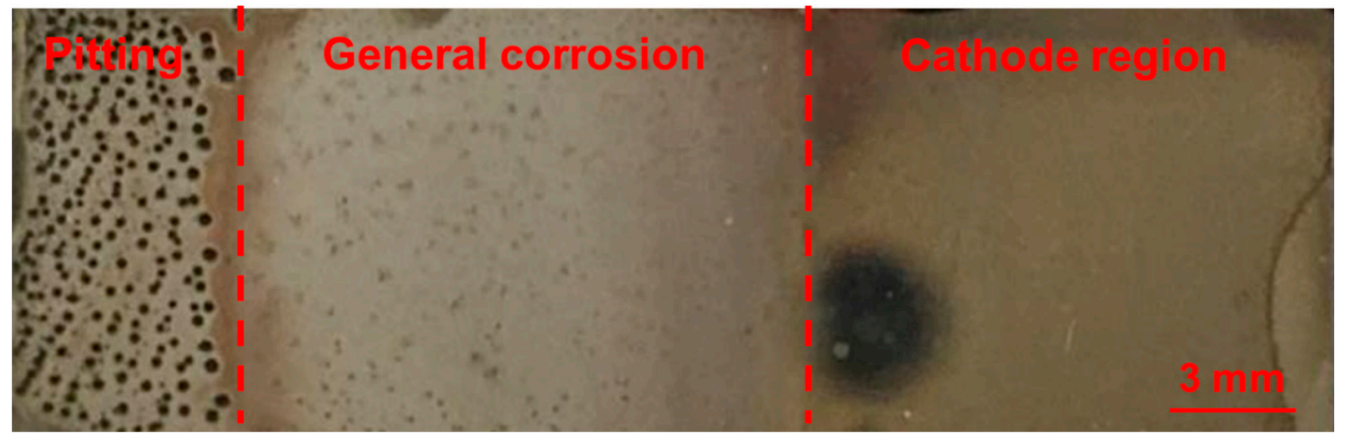

Figure 4. Appearance of the $30 \mathrm{~mm}$ long BPE after bipolar electrochemistry testing for $30 \mathrm{~min}$, with the left side showing large pits at the oxidation edge and the right side showing the reduction edge.

All observed pits were open pits without lacy metal covers. The region containing pits had a length of $6 \mathrm{~mm}$ measured from the oxidation edge, with general corrosion thereafter observed until a depth of $17 \mathrm{~mm}$ was reached. The remaining $13 \mathrm{~mm}$ of the BPE was the cathodic region. The boundary between the anodic and cathodic site was not in the centre of the BPE electrode, due to non-symmetric differences in the anodic vs. cathodic current response. By comparing the corrosion response along the BPE and the potential distribution from Figure $1 b$, the critical pitting potential was estimated to be around $+0.9 \mathrm{~V}_{\mathrm{OCP}}$ for this sample.

To identify the earliest onset of pit nucleation, the bipolar polarisation was applied for $5 \mathrm{~s}$ only, with Figure 5a highlighting the typical pit nucleation sites (labelled with arrows). From the EDX maps, a strong $\mathrm{Cr}$ and $\mathrm{C}$ signal confirms that the observed particles here were all chromium rich carbides. Localised corrosion was initiated at the interface between chromium carbides and the matrix, caused by either micro-galvanic effects [21] or Cr depletion [28], in combination with occluded crevice geometries around some of these carbides [29]. Chromium carbides are typically more electrochemical noble, so they can easily act as cathodes, and the surrounding matrix can act as the anode [21]. The associated $\mathrm{Cr}$ depleted regions are typically caused by $\mathrm{Cr}$ diffusion to form chromium carbides. These regions contain significantly reduced $\mathrm{Cr}$ concentrations and are not able to form stable passive films, especially in low $\mathrm{Cr}$ containing ferritic stainless steels [28]. Figure 5b shows the EDX map of a pit with a diameter of $5 \mu \mathrm{m}$, showing a large number of chromium carbides inside the dissolved pit volume. Chromium carbides dropped into the formed pit cavity after the surrounding stainless steel was corroded away, with the carbides remaining inside this cavity due to their higher electrochemical nobility.

Figure 6 summarises the images of the region containing pitting corrosion after 5 min of bipolar electrochemistry exposure. Figure 6a shows a pit with a diameter of $80 \mu \mathrm{m}$, surrounded by small voids which are indicative of the nucleation of several metastable pits. The circumference of the pit contained a ring of general corrosion. Pit growth ultimately results in the formation of an aggressive electrolyte (low $\mathrm{pH}$, high $\mathrm{Cl}^{-}$concentration) inside the pit [30]. The electrolyte can diffuse out and corrode the matrix surrounding the pit mouth, before the solution dilutes. Figure $6 \mathrm{~b}$ shows a higher magnification image of the pit mouth, with chromium carbides protruding out of the matrix, supporting the notion of their higher corrosion resistance. 
a
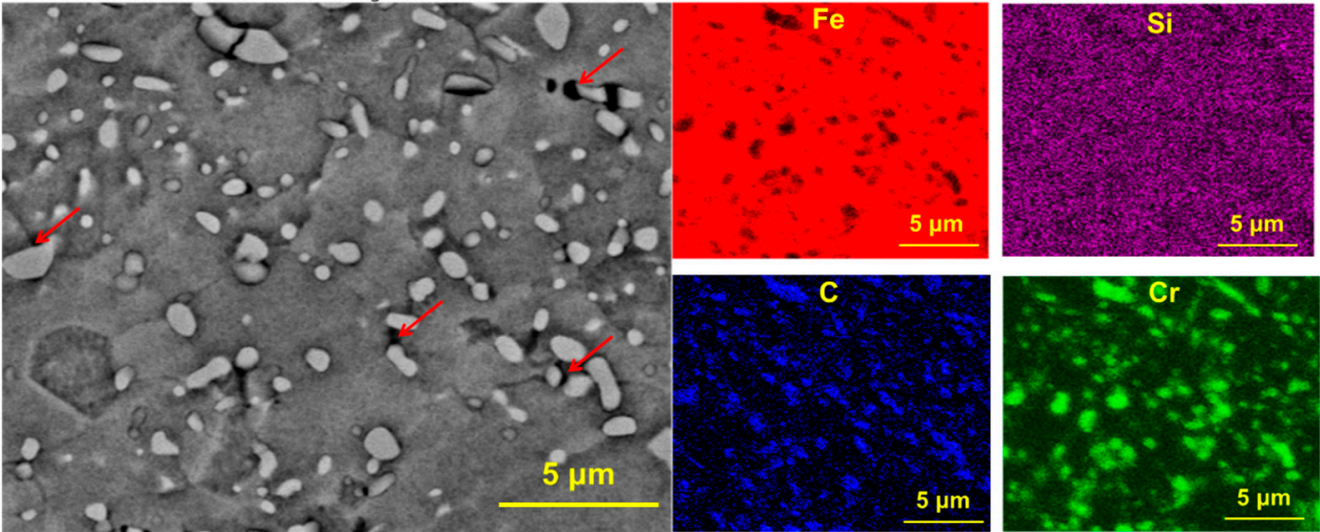

b
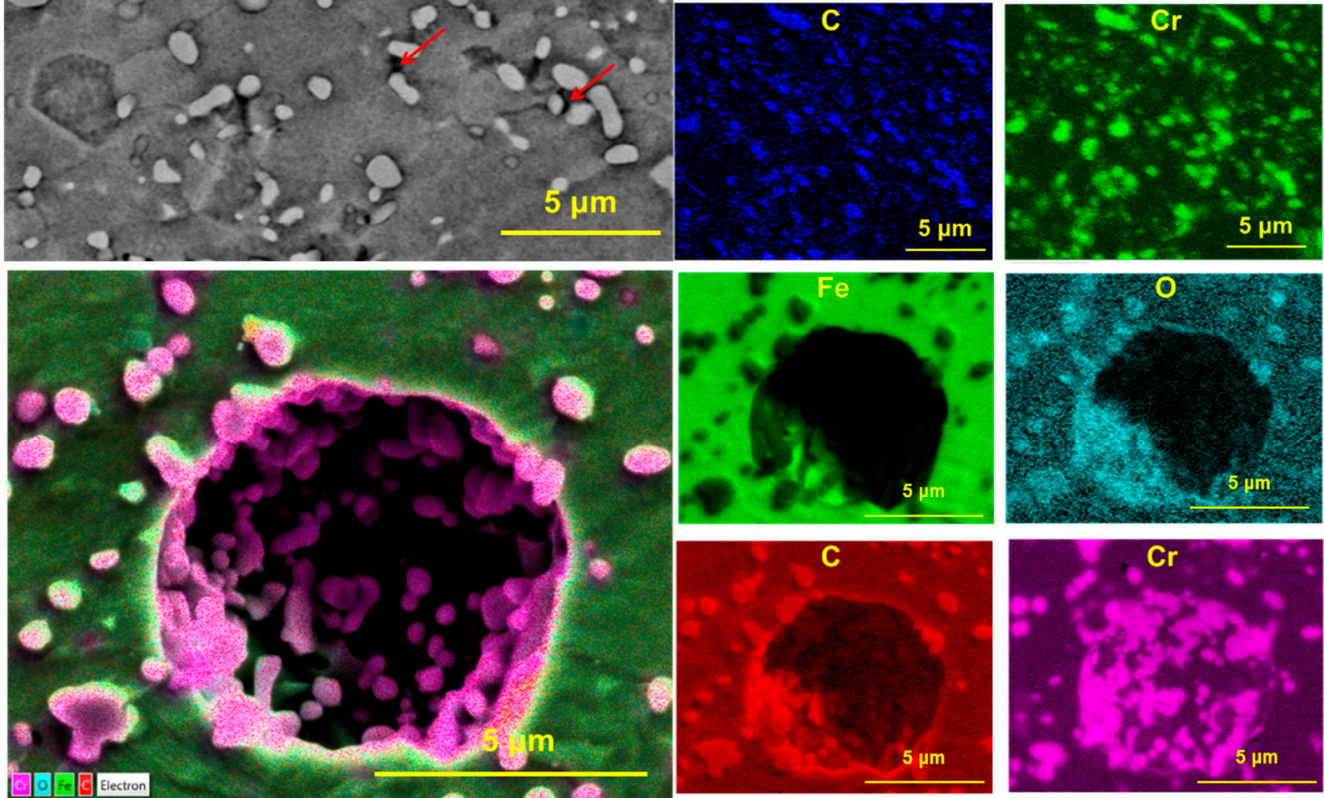

Figure 5. (a) SEM images with EDX maps of Type 420 stainless steel after $5 \mathrm{~s}$ exposure time, with the arrow highlighting a pit nucleation site, and (b) EDX maps of a pitting with 5 um diameter with corresponding EDX maps.

a

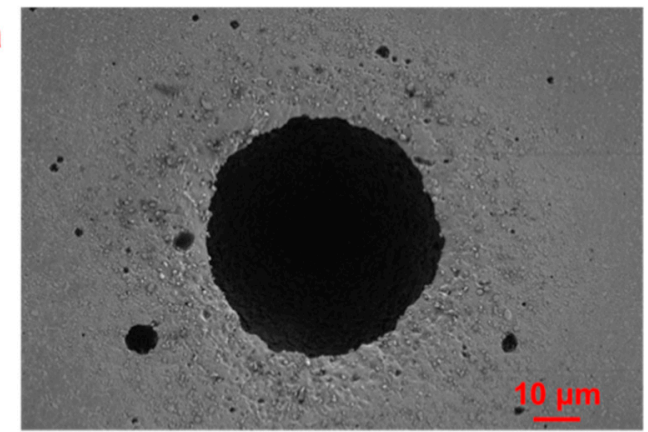

c

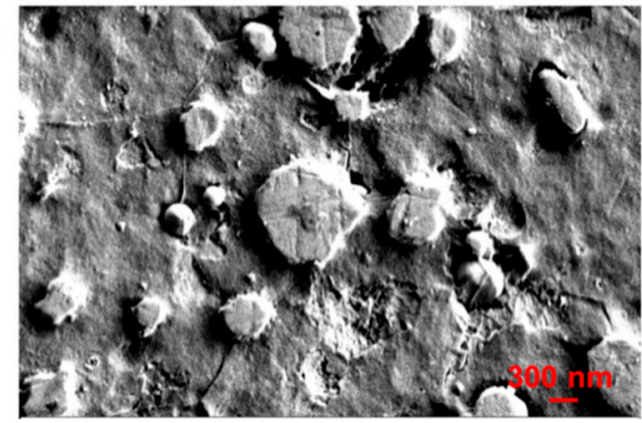

b

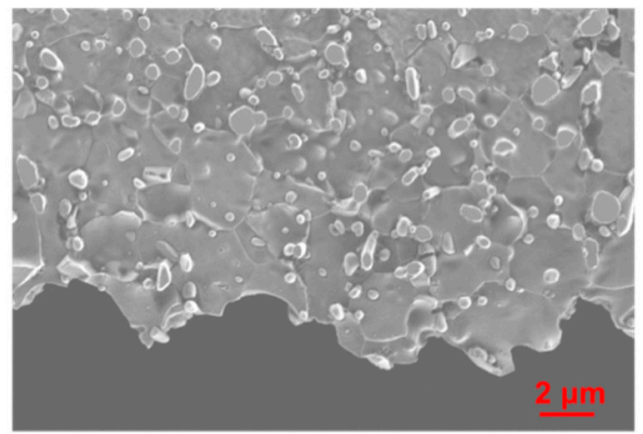

d

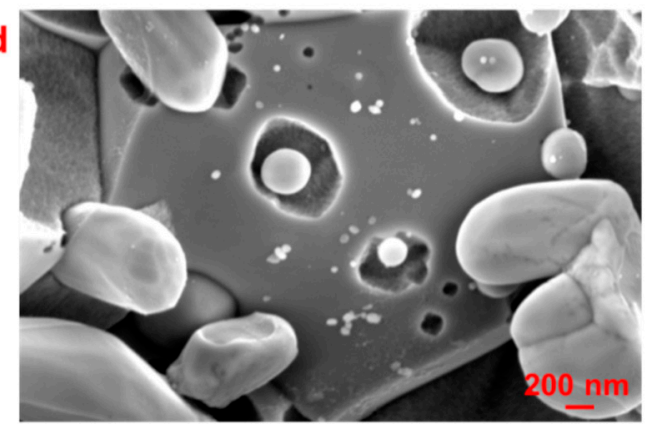

Figure 6. (a) SEM image of a pit with a corroded circumference, (b) higher magnification image of the corroded circumference of the pit, (c) the corroded outer part of the pit ring, and (d) SEM image of the pit bottom. 
Figure 6c provides another SEM image of the outer part of the corroded pit circumference, with Figure 6d showing an SEM image of the pit bottom. Grains with different heights can be seen, with larger sized chromium carbides at the surface. The cavities near the chromium carbides point towards the localised dissolution of the Type 420 matrix.

\subsection{General Corrosion Behaviour}

Figure 7 shows SEM images of the general corrosion region in Figure 4 after polarising the BPE for $30 \mathrm{~min}$. A large number of chromium carbides are also here protruding out of the matrix in the corroded regions. Individual grains of the corroded matrix can be seen, with Figure $7 \mathrm{~b}$ showing chromium carbides with typical sizes of $\approx 200 \mathrm{~nm}$ located at a grain boundary. The spherical shaped carbides remained at the grain surface, and ellipsoid chromium carbides were embedded within the matrix. Grains with different heights were observed within the general corrosion region, which were covered by fin-like surface structures, as shown in Figure 7c,d. The presence of these fins points towards the formation of $\alpha$-FeOOH with sedimentary amorphous layers, which have been reported to be either whisker, rod, or fin shaped [31]. $\alpha$-FeOOH is generally transformed from $\gamma$-FeOOH, via the formation of $\mathrm{Fe}_{3} \mathrm{O}_{4}[32,33]$. The presence of $\gamma-\mathrm{FeOOH}$ and $\alpha$-FeOOH can improve the corrosion resistance, as they are stable and protective passive films. However, $\mathrm{Fe}_{3} \mathrm{O}_{4}$ reduces the corrosion resistance, as highly conductive properties result in cathode, which accelerates the corrosion in the matrix [34,35].

a

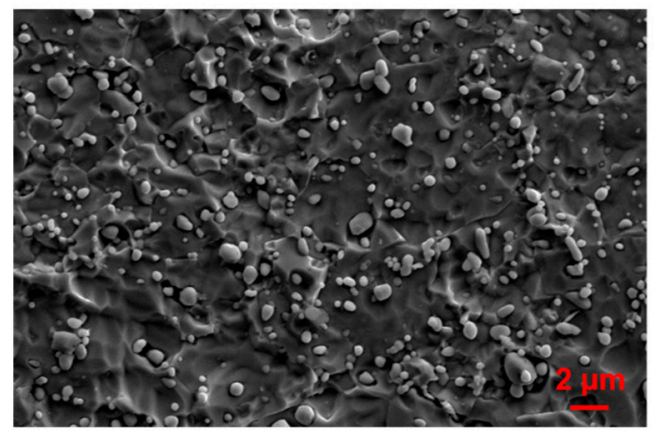

c

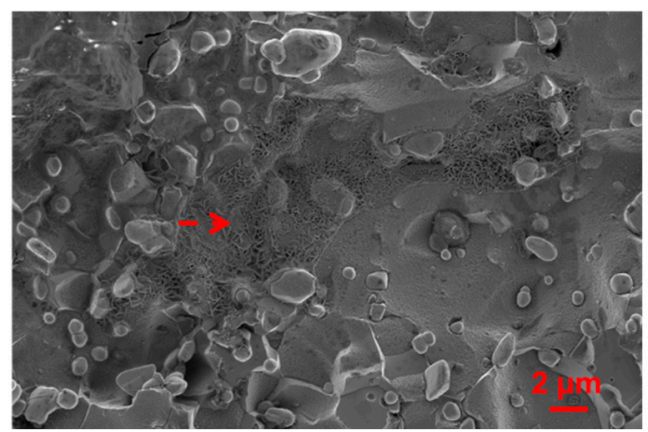

b

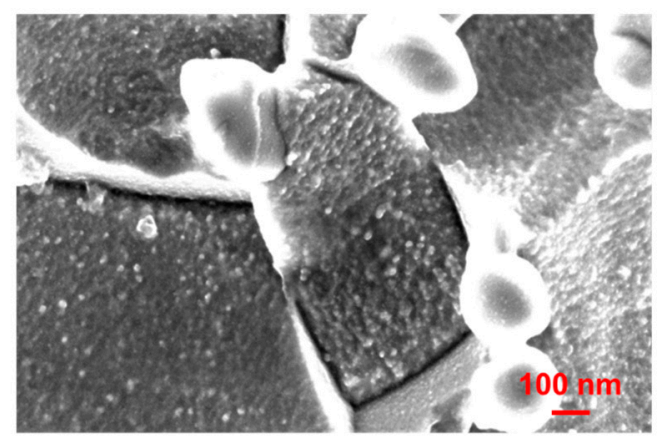

d

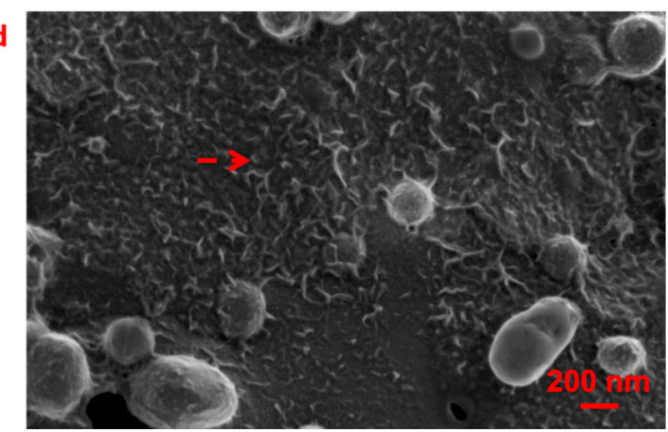

Figure 7. General corrosion on the BPE, with (a) carbides protruding out of the matrix, (b) grains with different heights and carbides at grain boundaries, and $(\mathbf{c}, \mathbf{d})$ the presence of $\mathrm{FeOOH}$.

Figure 8 shows images of the cathodic site of the BPE, containing discrete particles. The particle length varied from $10 \mu \mathrm{m}$ to $50 \mu \mathrm{m}$, and their presence is believed to be related to local electrochemical reactions. The EDX spectrum showed carbon, chloride, and oxygen rich particles, which could be easily removed by soap water cleaning.

$\mathrm{Cl}_{2}$ and $\mathrm{HClO}$ are generated from electrochemical reactions in $\mathrm{HCl}$ electrolyte under high applied potentials [36]. Dissolved $\mathrm{Cl}_{2}$ gas results in highly active oxidants: $\mathrm{Cl}_{2} \mathrm{O}, \mathrm{ClO}_{2}, \mathrm{ClO}^{-}, \mathrm{HClO} \mathrm{Cl}^{*}$, and $\mathrm{HO}_{2}{ }^{*}$ (* indicates reactive free radicals) [36]. These highly active oxidants can diffuse to the cathodic sites and be deposited on the sample surface via electrochemical deposition reactions. 

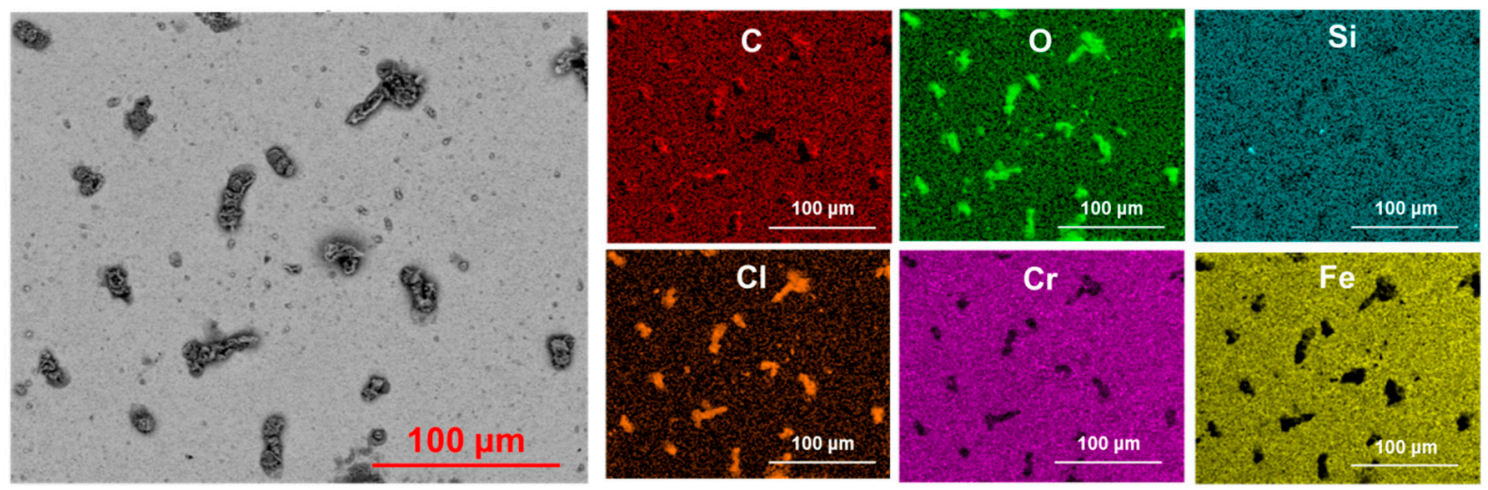

Figure 8. SEM images and corresponding EDX images of the cathodic region on the BPE.

\subsection{Pitting Corrosion Kinetics}

The advantage of applying bipolar electrochemistry to pitting corrosion studies lies in the ability to observe pit nucleation and growth along the surface of the BPE, i.e., along the acting potential gradient. This allows researchers to investigate the earliest onset of pitting, the determination of pit growth kinetics, and associated pit coalescence.

An example of this is shown in Figure 9, which shows the $50 \mathrm{~mm}$ long BPE after exposure to bipolar electrochemistry for $30 \mathrm{~min}$. Here, on the longer electrode, four distinct regions can clearly be seen along the BPE surface, labelled A-D. The left side of the BPE is the BPE oxidation edge, which had the highest degree of localised corrosion. Closer inspection of the regions revealed the presence of a large crevice around the edge of the sample and pitting corrosion surrounded by general corrosion, followed by a region with pitting corrosion only, general corrosion only, and no corrosion at all. The latter is indicative of the cathodic region. All the observed pits were open pits with a lower applied potential, resulting in general corrosion.

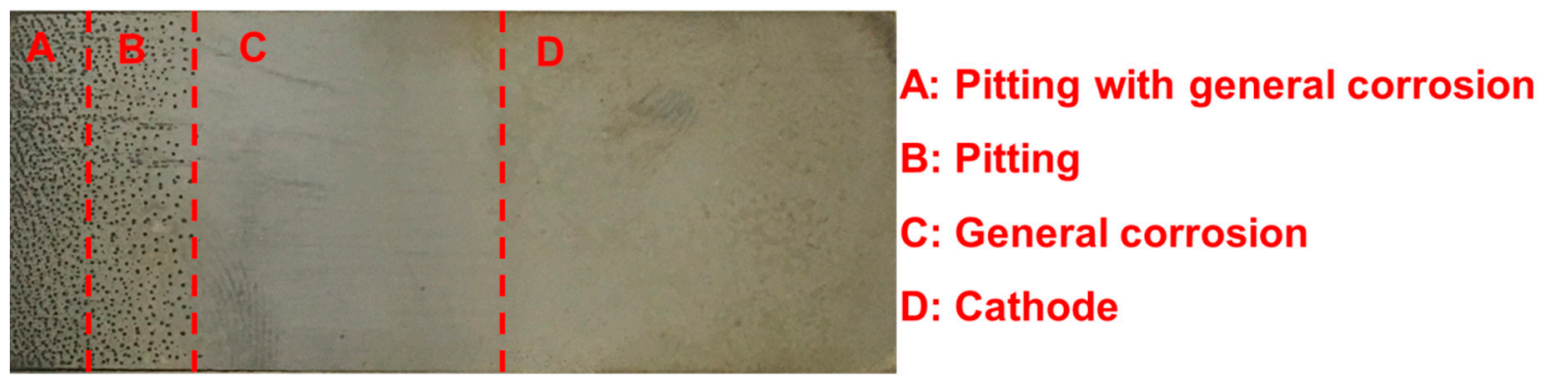

Figure 9. The surface appearance of the $50 \mathrm{~mm}$ long BPE after $30 \mathrm{~min}$ bipolar exposure.

Figure 10a shows an optical image of the oxidation edge, highlighting the crevice, and both regions containing pits (A, B) from Figure 9. Close to the oxidation edge, pitting with general corrosion can be observed with a higher pit density. At a lower acting potential (further to the right), only pitting corrosion can be observed, with far fewer nucleated pits. Figure 10b shows the 3D images of these regions, supporting the presence of a heavily corroded crevice, which developed between the BPE and the surrounding resin.

The pit covered region in Figure 9 was divided into seven sub-regions, each with a size of $1.5 \times 4 \mathrm{~mm}^{2}$ (length $\times$ width), as shown in Figure 11a. Region I represented the highest potential close to the oxidation edge, with region VII representing the lowest applied potential, 9 to $10.5 \mathrm{~mm}$ away from the oxidation edge. Region I contained the pit region with crevice, with regions II to IV showing pitting corrosion with general corrosion, whereas in regions V to VII, only pitting corrosion was observed. The pit density was reduced from region I to VII, with pits clearly coalesced in regions I, II, and III. The presence of numerous pits close to each other was found in regions IV and V, and predominantly isolated pits were found in regions VI and VII. 


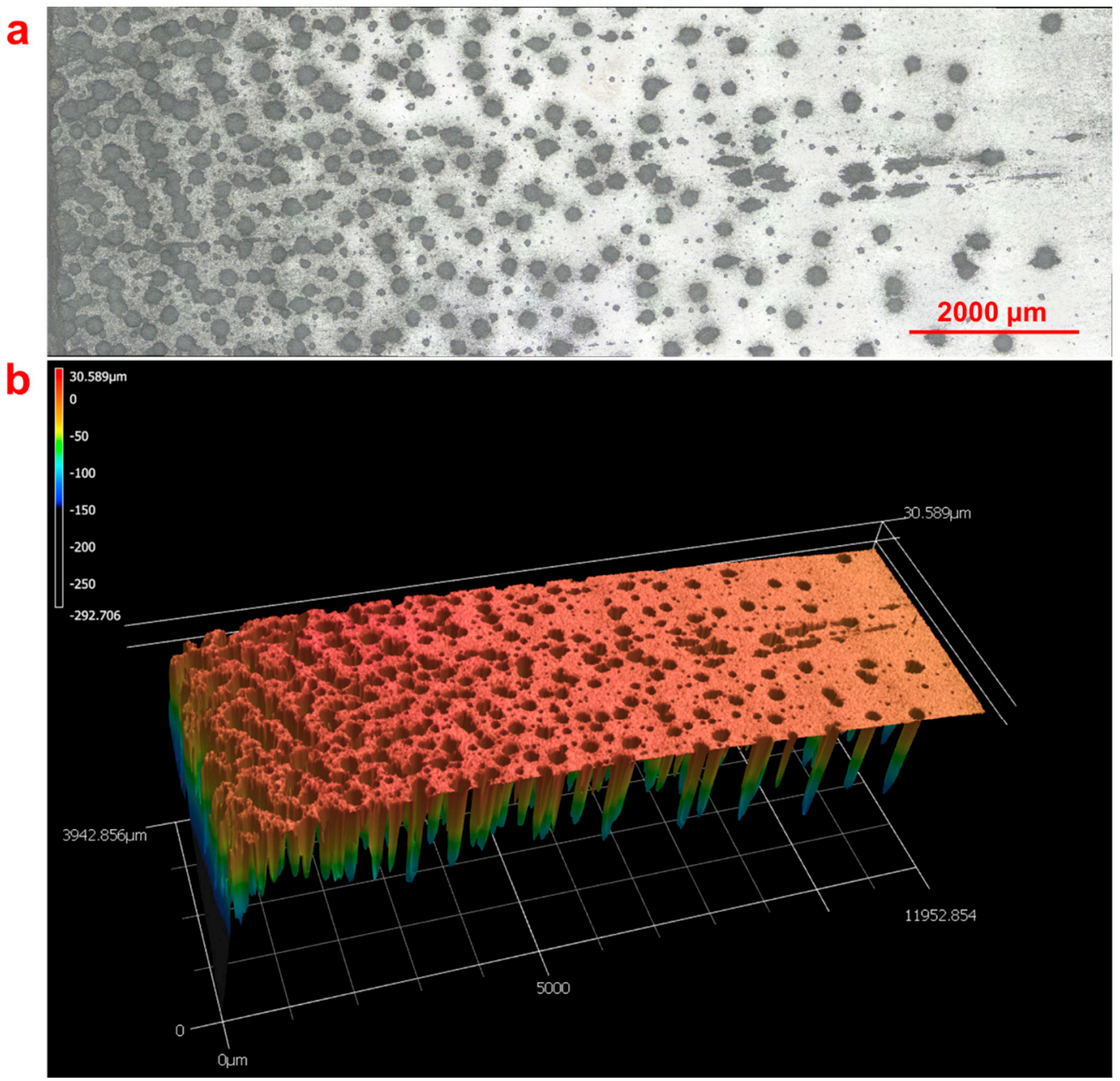

Figure 10. (a) The optical image of the pitting corrosion region on BPE $(50 \mathrm{~mm})$, and (b) the corresponding 3D laser confocal image of this region.

Figure $11 \mathrm{~b}$ shows the total dissolved pit volume in each of the seven regions, with the highest volume determined in region I and the lowest in region VII. The pit volume reduced exponentially from the BPE oxidation edge to the centre. Since the potential was linearly distributed along the length of the sample, an exponential potential vs. current relationship could be assumed [37].

Figure 12a gives the number of pits with their corresponding pit volumes as a function of the seven investigated regions, with the reported data obtained via laser confocal microscopy. From regions III to VII, i.e., along a decreasing potential, the number and volume of pits decreased. Regions I and II gave a slightly different response, with fewer pits but typically larger volumes. This observation is linked to the presence of a crevice in region I and the coalescence of larger pits in regions closer to the oxidation edge. From regions IV to VII, the pit numbers and the pit volumes were both clearly reduced, following the expected trend of fewer and smaller pits at lower applied potentials.

Figure 12a describes the sizes of all pits found in regions I to VII, providing information about the total number of pits and their size distributions. The largest pits in regions II to VII had maximum values of $10^{+6.7}\left(0.005 \mathrm{~mm}^{3}\right)$ to $10^{+7} \mu \mathrm{m}^{3}\left(0.01 \mathrm{~mm}^{3}\right)$. Since the exposure time was constant for all regions, a lower slope here indicated that more pits with smaller volumes grew, pointing towards a higher pit nucleation frequency. The overall shapes of all the curves shown in Figure 12a had similar features. Most of the curves contained two kinks, with one around a pit volume of $10^{+6.2} \mu \mathrm{m}^{3}$ $\left(\approx 0.002 \mathrm{~mm}^{3}\right)$ and the second around $10^{+6.6} \mu \mathrm{m}^{3}\left(\approx 0.004 \mathrm{~mm}^{3}\right)$, defined by the different slopes in Figure 12a. These are also highlighted by the two horizontal lines. 
a

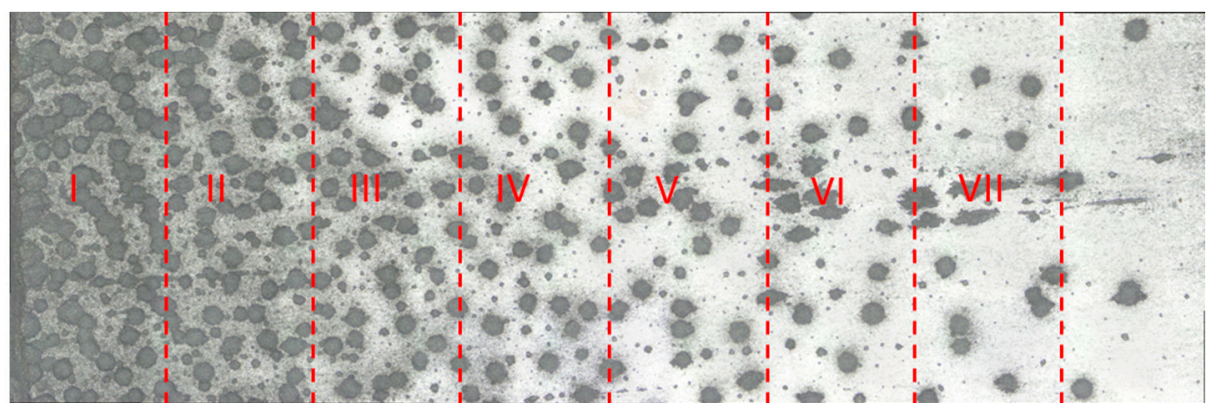

$2000 \mu \mathrm{m}$

b

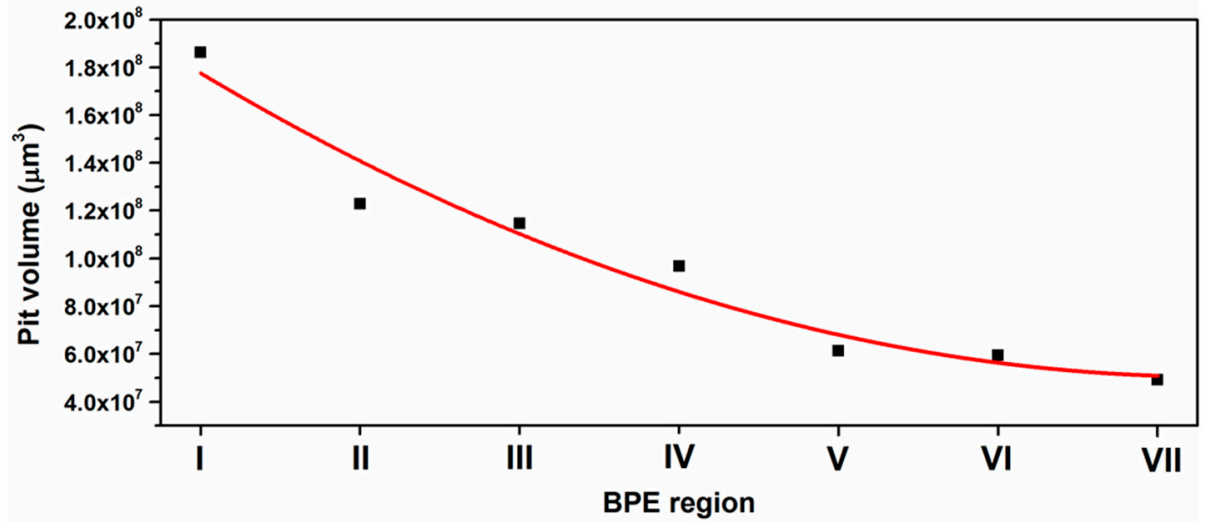

Figure 11. (a) Overview of the seven pit covered regions, with (b) the corresponding pit volumes measured using laser confocal microscopy.
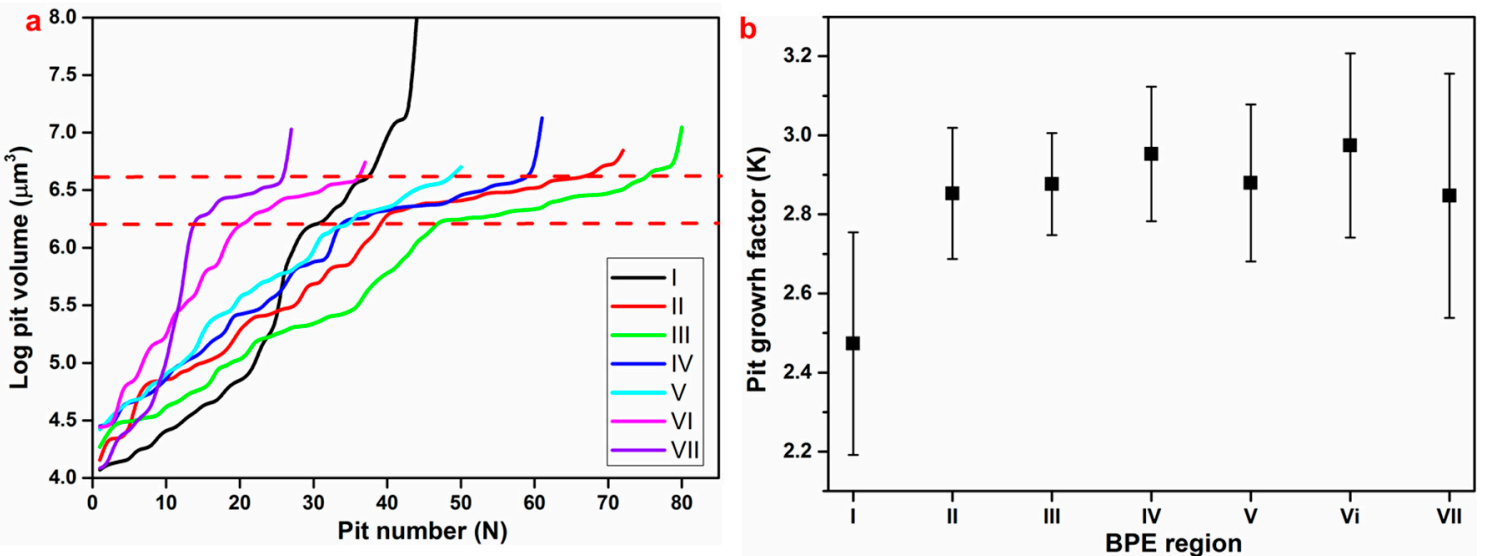

Figure 12. (a) The relationship between pit number and corresponding pit volumes, and (b) the corresponding pit growth factor (K) for each region (I-VII) in Figure 11.

The first kink can be explained for pits transforming from metastable to stable pit volumes, as the pit depth and overall volume act as diffusion lengths to stabilise pit growth [38]. The number of pits with stable and metastable volumes was not the same for all regions. The second kink possibly indicates the development of champion pits or pits that coalesced, resulting in significantly larger pit volumes. If we assume hemispherical pit shapes, the measured pit volumes would translate to a depth of $100 \mu \mathrm{m}$ for achieving stable pit growth in this material. This means that at least two distinct populations of pits were present, defined by the observed critical volume. A number of smaller pits with dimensions up to the critical volume of $10^{+6.2} \mu \mathrm{m}^{3}\left(\approx 0.002 \mathrm{~mm}^{3}\right)$, followed by a larger accumulation of pits that were slightly larger, are present, evident by the lower slope of the curve defining larger pits.

Figure $12 \mathrm{~b}$ gives the average pit growth factor calculated from the deepest ten pits in each of the seven regions, with the error bar defined by the standard deviation of these measurements. The deepest 
pits were assumed to nucleate at $\mathrm{t}=0 \mathrm{~s}$, with pit growth kinetics following the power law relationship in Equation (1) [39]:

$$
\mathrm{d}=\mathrm{Kt}^{\mathrm{b}}
$$

where $(d)$ is the pit depth $(\mu \mathrm{m}), t$ is time $(\mathrm{s})$, and $\mathrm{K}$ and $\mathrm{b}$ are experimental constants. The latter are influenced by the temperature and $\mathrm{pH}$ value of the electrolyte, with typical values of $(\mathrm{b})$ from 0.3 to 0.5 . If we assume the value of $b=0.5$, with $d$ measured from the laser confocal microscopy, the value of $K$ can be calculated for each region.

The obtained $\mathrm{K}$ values in Figure $12 \mathrm{~b}$ confirm that the pit growth kinetics here were independent of the acting potential in each region. The 10 largest pits in each region had similar dimensions, resulting in pit growth factors (K) of around 2.9 from region II to IV. In region I, K was far lower at 2.5. The difference in pit growth kinetics in region (I) was caused by several pits merging together, reducing the number of larger pits seen in the overall distribution in Figure 12a. The presence of crevice corrosion also affected the maximum current up-take in this region, which most likely also contributed to a reduced pit growth factor. The coalescence of pits is also expected to affect the acting local potential, in parallel influencing pit growth kinetics [40].

The results reported in this investigation demonstrate the versatility of bipolar electrochemistry testing for corrosion research, providing access to a broad range of corrosion behaviours and mechanisms. In contrast, by using the conventional three-electrode polarisation set-up, a similar breadth of results can only be achieved by undertaking a large number of potentio-static polarisation experiments at different set potentials. With the bipolar screening technique, the occurrence of metastable pits, associated critical pitting potentials, and pit growth factors, as well as pit nucleation sites, can be measured along one sample surface, in combination with far shorter experimental exposure times. The bipolar technique is, however, neither perfect nor fully understood yet, but the described advantages certainly warrant the further application and exploration of this method as a corrosion assessment tool.

\section{Conclusions}

(1) Bipolar electrochemistry allows a broad range of corrosion responses to be observed in a single experiment.

(2) $\mathrm{Cr}_{23} \mathrm{C}_{6}, \mathrm{Cr}_{3} \mathrm{C}_{2}$, and $\mathrm{Cr}_{7} \mathrm{C}_{3}$ are present in Type 420 stainless steel, with pits nucleating near these chromium-rich carbides.

(3) Pit nucleation, growth, and coalescence have been observed.

(4) Pit growth kinetics are independent of the acting potential.

(5) A critical pit volume for the transition from metastable to stable pits has been determined.

Author Contributions: Y.Z.: conceptualization, methodology, validation, formal analysis, investigation, data curation, writing — original draft, visualization, funding acquisition; D.L.E.: conceptualization, methodology, validation, formal analysis, investigation, funding acquisition, writing-review and editing, supervision. All authors have read and agreed to the published version of the manuscript.

Funding: This research received no external funding.

Conflicts of Interest: The authors declare no conflict of interest.

\section{References}

1. Zhou, Y.; Engelberg, D.L. Application of a modified bi-polar electrochemistry approach to determine pitting corrosion characteristics. Electrochem. Commun. 2018, 93, 158-161. [CrossRef]

2. Munktell, S.; Tydén, M.; Högström, J.; Nyholm, L.; Björefors, F. Bipolar electrochemistry for high-throughput corrosion screening. Electrochem. Commun. 2013, 34, 274-277. [CrossRef]

3. Pébère, N.; Vivier, V. Local Electrochemical Measurements in Bipolar Experiments for Corrosion Studies. ChemElectroChem 2016, 3, 415-421. [CrossRef]

4. Crooks, R.M. Principles of Bipolar Electrochemistry. ChemElectroChem 2016, 3, 357-359. [CrossRef] 
5. Wiesener, K.; Ohms, D.; Benczúr-Ürmössy, G.; Berthold, M.; Haschka, F. High power metal hydride bipolar battery. J. Power Sources 1999, 84, 248-258. [CrossRef]

6. Sequeira, C.A.C.; Cardoso, D.S.P.; Gameiro, M.L.F. Bipolar Electrochemistry, a Focal Point of Future Research. Chem. Eng. Commun. 2016, 203, 1001-1008. [CrossRef]

7. Qi, Z.; You, S.; Ren, N. Wireless Electrocoagulation in Water Treatment Based on Bipolar Electrochemistry. Electrochim. Acta. 2017, 229, 96-101. [CrossRef]

8. Yi, Y.; Cho, P.; Al Zaabi, A.; Addad, Y.; Jang, C. Potentiodynamic polarization behaviour of AISI type 316 stainless steel in $\mathrm{NaCl}$ solution. Corros. Sci. 2013, 74, 92-97. [CrossRef]

9. Krawczyk, B.; Cook, P.; Hobbs, J.; Engelberg, D. Corrosion Behavior of Cold Rolled Type 316L Stainless Steel in $\mathrm{HCl}$ Containing Environments. Corrosion 2017, 73, 1346. [CrossRef]

10. Moayed, M.H.; Newman, R.C. Evolution of current transients and morphology of metastable and stable pitting on stainless steel near the critical pitting temperature. Corros. Sci. 2006, 48, 1004-1018. [CrossRef]

11. Al Saadi, S.; Yi, Y.; Cho, P.; Jang, C.; Beeley, P. Passivity breakdown of 316L stainless steel during potentiodynamic polarization in $\mathrm{NaCl}$ solution. Corros. Sci. 2016, 111, 720-727. [CrossRef]

12. Pistorius, P.C.; Burstein, G.T. Metastable Pitting Corrosion of Stainless Steel and the Transition to Stability. Philos. Trans. R. Soc. A Math. Phys. Eng. Sci. 1992, 341, 531-559.

13. Laycock, N.J. Metastable Pitting and the Critical Pitting Temperature. J. Electrochem. Soc. 1998, 145, 2622. [CrossRef]

14. Örnek, C.; Léonard, F.; McDonald, S.A.; Prajapati, A.; Withers, P.J.; Engelberg, D.L. Time-dependent in situ measurement of atmospheric corrosion rates of duplex stainless steel wires. npj Mater. Degrad. 2018, 2, 1-15.

15. Eguchi, K.; Burnett, T.L.; Engelberg, D.L. X-Ray tomographic characterisation of pitting corrosion in lean duplex stainless steel. Corros. Sci. 2019, 165, 108406. [CrossRef]

16. Bond, A.P.; Dundas, H.J. Effects of Composition on the Stress Corrosion Cracking of Ferritic Stainless Steels. Corrosion 2013, 24, 344-352. [CrossRef]

17. Newberg, R.T.; Uhlig, H.H. Stress Corrosion Cracking of $18 \%$ Cr Ferritic Stainless Steels. J. Electrochem. Soc. 1972, 119, 981. [CrossRef]

18. Yin, Z.F.; Wang, X.Z.; Liu, L.; Wu, J.Q.; Zhang, Y.Q. Characterization of corrosion product layers from CO2corrosion of 13Cr stainless steel in simulated oilfield solution. J. Mater. Eng. Perform. 2011, 20, 1330-1335. [CrossRef]

19. Anantha, K.H.; Örnek, C.; Ejnermark, S.; Medvedeva, A.; Sjöström, J.; Pan, J. In Situ AFM Study of Localized Corrosion Processes of Tempered AISI 420 Martensitic Stainless Steel: Effect of Secondary Hardening. J. Electrochem. Soc. 2017, 164, C810-C818. [CrossRef]

20. Lei, X.; Feng, Y.; Zhang, J.; Fu, A.; Yin, C.; Macdonald, D.D. Impact of Reversed Austenite on the Pitting Corrosion Behavior of Super 13Cr Martensitic Stainless Steel. Electrochim. Acta. 2016, 191, 640-650. [CrossRef]

21. Anantha, K.H.; Örnek, C.; Ejnermark, S.; Medvedeva, A.; Sjöström, J.; Pan, J. Correlative Microstructure Analysis and In Situ Corrosion Study of AISI 420 Martensitic Stainless Steel for Plastic Molding Applications. J. Electrochem. Soc. 2017, 164, C85-C93. [CrossRef]

22. Candelaria, A.F.; Pinedo, C.E. Influence of the heat treatment on the corrosion resistance of the martensitic stainless steel type AISI 420. J. Mater. Sci. Lett. 2003, 22, 1151-1153. [CrossRef]

23. Nakagawa, H.; Miyazaki, T. Effect of retained austenite on the microstructure and mechanical properties of martensitic precipitation hardening stainless steel. J. Mater. Sci. 1999, 34, 3901-3908. [CrossRef]

24. de Moor, E.; Lacroix, S.; Clarke, A.J.; Penning, J.; Speer, J.G. Effect of retained austenite stabilized via quench and partitioning on the strain hardening of martensitic steels. Metall. Mater. Trans. A Phys. Metall. Mater. Sci. 2008, 39, 2586-2595. [CrossRef]

25. Godec, M.; Balantič, D.A.S. Coarsening behaviour of M23C6 carbides in creep-resistant steel exposed to high temperatures. Sci. Rep. 2016, 6, 29734. [CrossRef] [PubMed]

26. Du Toit, M.; Van Rooyen, G.T.; Smith, D. Heat-affected zone sensitization and stress corrosion cracking behaviour of 12\% chromium type 1.4003 ferritic stainless steel. Weld. World 2007, 51, 41-50. [CrossRef]

27. Bjärbo, A.; Hättestrand, M. Complex carbide growth, dissolution, and coarsening in a modified 12 pet chromium steel-an experimental and theoretical study. Metall. Mater. Trans. A Phys. Metall. Mater. Sci. 2001, 32, 19-27. [CrossRef]

28. Gellings, P.J.; de Jongh, M.A. Grain boundary oxidation and the chromium-depletion theory of intercrystalline corrosion of austenitic stainless steels. Corros. Sci. 1967, 7, 413-421. [CrossRef] 
29. Jung, K.; Oh, K.; Nam, D.H.; Ahn, S.; Oh, S.; Kwon, H. Effects of Centerline Segregation of Cr Carbides and Non-Metallic Inclusions on the Pitting Corrosion of Fe-13Cr-0.3C Stainless Steel Produced by Continuous Casting and Strip Casting. Corrosion 2017, 73, 979-987. [CrossRef]

30. Frankel, G.S.; Stockert, L.; Hunkeler, F.; Boehni, H. Metastable pitting of stainless steel. Corrosion 1987, 43, 429-436. [CrossRef]

31. Liu, J.; Wong, L.M.; Wong, L.H.; Chiam, S.Y.; Li, S.F.; Ren, Y. Immobilization of dye pollutants on iron hydroxide coated substrates: kinetics, efficiency and the adsorption mechanism. J. Mater. Chem. A 2016, 4, 13280-13288. [CrossRef]

32. N Dai, N.; Zhang, J.; Chen, Q.; Yi, B.; Cao, F.; Zhang, J. Effect of the direct current electric field on the initial corrosion of steel in simulated industrial atmospheric environment. Corros. Sci. 2015, 99, 295-303. [CrossRef]

33. Asami, K.; Kikuchi, M. In-depth distribution of rusts on a plain carbon steel and weathering steels exposed to coastal-industrial atmosphere for 17 years. Corros. Sci. 2003, 45, 2671-2688. [CrossRef]

34. Hao, L.; Zhang, S.; Dong, J.; Ke, W. Evolution of corrosion of MnCuP weathering steel submitted to wet/dry cyclic tests in a simulated coastal atmosphere. Corros. Sci. 2012, 58, 175-180. [CrossRef]

35. Stratmann, M.; Bohnenkamp, K.; Ramchandran, T. The influence of copper upon the atmospheric corrosion of iron. Corros. Sci. 1987, 27, 905-926. [CrossRef]

36. Ignatov, I.; Mosin, O.; Gluhchev, G.; Karadzhov, S.; Miloshev, G.; Ivanov, N. Studying Electrochemically Activated $\mathrm{NaCl}$ Solutions of Anolyte and Catholyte by Methods of Non-Equilibrium Energy Spectrum (NES) and Differential Non-Equilibrium Energy Spectrum (DNES). J. Med. Physiol. Biophys. 2016, 20, 13-23.

37. Duval, J.; Kleijn, J.M.; Van Leeuwen, H.P. Bipolar electrode behaviour of the aluminium surface in a lateral electric field. J. Electroanal. Chem. 2001, 505, 1-11. [CrossRef]

38. Tian, W.; Li, S.; Du, N.; Chen, S.; Wu, Q. Effects of applied potential on stable pitting of 304 stainless steel. Corros. Sci. 2015, 93, 242-255. [CrossRef]

39. Ernst, P.; Newman, R.C. Pit growth studies in stainless steel foils. I. Introduction and pit growth kinetics. Corros. Sci. 2002, 44, 927-941.

40. Laycock, N.J.; Krouse, D.P.; Hendy, S.C.; Williams, D.E. Computer Simulation of Pitting Corrosion of Stainless Steels. Electrochem. Soc. Interface 2014, 23, 65-71. [CrossRef]

(C) 2020 by the authors. Licensee MDPI, Basel, Switzerland. This article is an open access article distributed under the terms and conditions of the Creative Commons Attribution (CC BY) license (http://creativecommons.org/licenses/by/4.0/). 